$\begin{array}{cl}\text { Türkiye Tarımsal Araştırmalar Dergisi } & \text { Turk J Agric Res } \\ \text { dergipark.gov.tr/tutad } & \text { 2018, 5(1): 9-18 } \\ \text { O TÜTAD } & \text { ISSN: 2148-2306 } \\ \text { e-ISSN: 2528-858X } & \text { doi: 10.19159/tutad.322336 }\end{array}$

\title{
Akselendi Ovası Tarım Topraklarının Temel Toprak Özellikleri ve Bitki Besin Elementi Durumlarının Belirlenmesi ve Dağılım Haritalarının Oluşturulması*
}

\author{
PInar ÇELIK, Orhan DENGIZZ** \\ Ondokuz Mayls Üniversitesi, Ziraat Fakültesi, Toprak Bilimi ve Bitki Besleme Bölümü, Samsun, TÜRKIYYE
}

\begin{tabular}{ll}
\hline \multicolumn{1}{c}{ Geliş Tarihi/Received: 19.06.2017 } & Kabul Tarihi/Accepted: 20.11.2017 \\
\hline ORCID ID (Yazar sirasina göre / by author order) & \\
(Dorcid.org/0000-0002-3085-6905 (Dorcid.org/0000-0002-0458-6016 & \\
"Sorumlu Yazar/ Corresponding Author: odengiz@omu.edu.tr &
\end{tabular}

Özet: Bu çalışma, Gediz Havzası içerisinde yer alan Ilıcak ve Kum Çayı iki bitișik mikro havza içerisinde Akselendi Ovası'nın da yer aldığı taban arazisi üzerinde gerçekleştirilmiştir. Çalışma alanı 9437.1 ha olup, bu alan üzerinde dağılım gösteren tarım topraklarının, temel bazı özellikleri ve mevcut verimlilik durumlarının belirlenmesi amacıyla yürütülmüștür. Ayrıca, belirlenen bu toprak özelliklerinin Ters Ağırlıklı Mesafe (IDW, Inverse Distance Weighted) enterpolasyon modeli yardımıyla alan içesinde dağılım haritalarının oluşturulması da amaçlanmıștır. Çalıșmada, tarım alanlarından toplam 181 adet toprak örneklemesi yapılmış, toprak örnekleri 0-30 cm derinlikten yer koordinatları ölçülerek alınmıştır. Alınan toprak örneklerinde; toprakların verimlilik analizleri (toprak bünyesi, $\mathrm{pH}$, elektriksel iletkenlik, kireç, organik madde) ve bitkiye yarayışlı makro ve mikro elementler (N, P, K, Fe, Cu, Zn ve Mn) analizleri yapılmıştır. Yapıllan analizler sonucunda, tarım arazileri genel olarak kaba bir bünyeye sahip olup, bünye killi tın ile kum arasında değişmektedir. Toprakların pH değerleri çok değişkenlik göstermemekle birlikte hafif alkali karakterli, organik madde bakımından büyük bir çoğunluğu az ve orta, tuzsuz ve \% 56.4'ü orta kireçli topraklar olduğu tespit edilmiştir. Ayrıca toprakların \% 52.4'ünde fosfor, \% 68.5'inde ise azot noksanlığı görülmektedir. Çalışma alanı topraklarının mikro element kapsamı yönünden sadece bakır içerikleri yeterli düzeyde iken; demir, mangan ve çinko içeriklerinde yetersizliklerin olduğu tespit edilmiştir.

Anahtar Kelimeler: Toprak bitki besin maddeleri, enterpolasyon, Akselendi Ovası

\section{Determination of Basic Soil Properties and Nutrient Element States of Agricultural Soils of Akselendi Plain and Formation of Distribution Maps}

\begin{abstract}
This study was carried out to determine some basic characteristics and present productivity status of agricultural lands covering 9437.1 hectares between two adjacent micro-basins, Ilıcak and Kum Rivers and Akselendi plain, in Gediz Basin. Additionally, it was also aimed to determine distribution maps of these soil properties in the area with IDW interpolation model. A total of 181 soil samples were collected, soil samples were collected between 0-30 cm depth while geographic coordinates were recorded the. Soil fertility (soil texture, $\mathrm{pH}$, electrical conductivity, calcium carbonate, organic matter), and available micro and macroelement contents (N, P, K, Fe, Cu, Zn, and $\mathrm{Mn}$ ) were analyzed in the collected soil samples. According to analysis results, agricultural lands have a coarse texture in general, while texture changes between a clay loam and sandy. Even though soil $\mathrm{pH}$ values do not change often, some were slightly alkaline, low or moderate on organic matter, salty, and $56.4 \%$ of the soil were mild limy. In addition, 52.4 and $68.5 \%$ of the soil were low in phosphorus and nitrogen, respectively. While only the copper content of the study area soil was sufficient in terms of microelement coverage; iron, manganese and zinc contents were found to be inadequate.
\end{abstract}

Keywords: Soil plant nutrient elements, interpolation, Akselendi Plain

\footnotetext{
": Bu çalışma; Ondokuz Mayıs Üniversitesi, Fen Bilimleri Enstitüsü, Yüksek Lisans Tez çalışmasından üretilmiștir.
} 


\section{Giriş}

Doğal kaynakların envanterlerinin detaylı bir şekilde bilinmesi, bu kaynakların yönetilmesi ve planlanması açısından gerekli bir faktördür. Sınırlı olan doğal kaynakların (toprak, su, hava, canlılar, maden yatakları vb.) sürdürülebilir şekilde kullanılabilmesi için mutlaka karakteristiklerinin belirlenmesi ve bu özelliklerin göz önünde bulundurularak planlamaların yapılması kaçınılmazdır. Günümüzde artık önemi daha da farkına varılan gerek biyofiziksel, gerekse de ekonomik olarak dikkate alınan önemli doğal kaynaklardan olan arazi ve toprakların kullanımları; faydalanıcılara sürdürülebilir bir şekilde yararlı olması için, sahip oldukları karakteristikler ve yetenekleri doğrultusunda kullanılması gerekmektedir.

Sürdürülebilir toprak verimliliği, uygun yönetim sistemleri altında toprakların niteliklerini bozmadan bitki üretme kapasitesidir (Pierce ve ark., 1983; Mueller ve ark., 2010). Gerek bu kapasiteyi, gerekse de toprakların ekosistem fonksiyonlarını ve sunmuş oldukları servisleri bozmadan optimum seviyede kullanılmaları, toprakların yakından tanınması ve bu tanımlamaya uygun işletilmesi ile mümkündür.

Doğal kaynakların korunması ve sürdürülebilir toprak verimliliğinde başarılı olabilmek için iklim faktörlerinin yanında; toprakta bitki besin maddesi miktar ve dengesi, toprak organik maddesinin korunması, münavebe, kontrollü toprak işleme, entegre hastalık-zararlı ve yabancı ot mücadelesi ve insan faktörü önem arz etmektedir. Bu faktörler dikkate alınarak uygun tarımsal yönetim yapılmalıdır. Bitkilerin yaşamaları için mutlak gerekli olan bazı mikro besin maddeleri ülkemiz tarımında yaygın olarak kullanılan ticari gübrelerin yapısında genellikle bulunmadığından, makro besin maddeleri gibi toprağa düzenli bir şekilde verilememektedir (Özyazıcı ve ark., 2016). Ayrıca, verim artışına dayalı tarım sistemlerinin uygulanması, topraktan yıkanma ile oluşan kayıplar, tek yönlü gübre uygulamaları gibi faktörler de toprakta mikro besin maddelerinin yarayışı miktarlarının azalmasına neden olmaktadır. Sonuç olarak toprakta makro besin maddeleri ile mikro besin maddeleri arasındaki denge giderek bozulmakta ve bitkilerin mikro besin elementlerinden yararlanması azalmaktadır.

$\mathrm{Bu}$ çalışmanın amacı; Gediz Havzası içerisinde yer alan Ilıcak ve Kum Çayı iki bitişik mikro havza içerisinde Akselendi Ovası'nın da yer aldığı taban arazisi üzerinde, yaklaşık 9437.1 hektarlık alan kaplayan tarım alanlarına ait toprakların, temel bazı özellikleri ve mevcut verimlilik durumlarının belirlenmesi ve belirlenen bu toprak özelliklerinin Ters Ağırlıklı Mesafe (IDW, Inverse Distance Weighted) enterpolasyon modeli yardımıyla alan içesinde dağılım haritalarının oluşturulmasıdir.

\section{Materyal ve Yöntem}

\section{1. Çalışma alanı ve yakın çevresine ait genel özellikler}

Bu çalışma, Gediz Havzası'nda bulunan bitişik iki mikro havzada (Ilıcak ve Kum Çayı) yürütülmüştür (Şekil 1). Çalışma alanı, yaklaşık 16.647 hektar alanı kaplamakta olup, deniz seviyesinden yüksekliği $70 \mathrm{~m}$ ile $760 \mathrm{~m}$ arasında değişmektedir (Şekil 2). Çalışma alanı, Akselendi Ovası'nın da yer aldığı taban arazisi üzerinde yaklaşık 9437.1 hektarlık alan kaplamaktadır. Yoğun tarımsal faaliyetlerde kullanılan bu alanlara ait topraklar, düz ve hafif eğim ve çoğunluğu alüvyal depozitlerle üzerinde oluşmuşlardır. $\mathrm{Bu}$ alanlar havzanın batı tarafinda taban arazileri oluştururken, çalışma alanının doğu ve kuzey-doğu kısmı havzanın dağlık kısımlara ait etek araziler oluşturmaktadır.

Gediz Nehri ve Kum Çayı gibi kolları boyundaki geniş bir alana yayılmış kumsallar, alüvyonlardan oluşmuştur. Havzada Menderes masifine bağlı granitlerle yer yer pegmatitler ve Akhisar'ın kuzey doğusunda geniş alanları kaplayan diorit, gabro ve peridotitler bulunmaktadır. Havzada genellikle tipik Akdeniz iklimi görülmekte olup, yıllık yağış ortalaması 603 $\mathrm{mm}$ ve yıllık ortalama sicaklık değerleri 13.5-16.6 ${ }^{\circ} \mathrm{C}$ arasında değişmektedir.

Çalışma alanı içerisinde ve yakın çevresinde dağılım gösteren arazi kullanımı/arazi örtüsü (AK/AÖ) türlerinin alansal ve oransal dağılımları Tablo 1 ve Şekil 3 'te verilmiştir. İki mikro havza içerisinde en fazla dağılıma sahip AK/AÖ türü yaklaşık \% $\quad 31$ ile sulanan tarım alanları oluşturmakta, zeytin yetiştiriciliği ise alanın $\% 5.1$ 'ini teşkil etmektedir.

\section{2. Örnekleme planı ve toprak analiz yöntemleri}

Yaklaşı1k 9437.1 hektarlık alan kaplayan havza tarım toprakları içerisinde $700 \mathrm{~m}$ x $700 \mathrm{~m}$ şeklinde oluşturulan grit sisteminden yüzeyden $(0-30 \mathrm{~cm})$ 181 adet toprak örneklemesi yapılmıştır. Toprak örneklemesine ait desen Şekil 4'te verilmiştir. Alınan bu örneklerin analizleri yapılmak üzere laboratuvara getirilmiş, laboratuvara getirilen örnekler kurutularak $2 \mathrm{~mm}$ elekten elenmiş ve analize hazırlanmıştır. Toprak örneklerinde; Bouyoucos hidrometre yöntemiyle bünye (Bouyoucos, 1951), Scheibler kalsimetresi ile volümetrik olarak kireç (Nelson, 1982), modifiye 


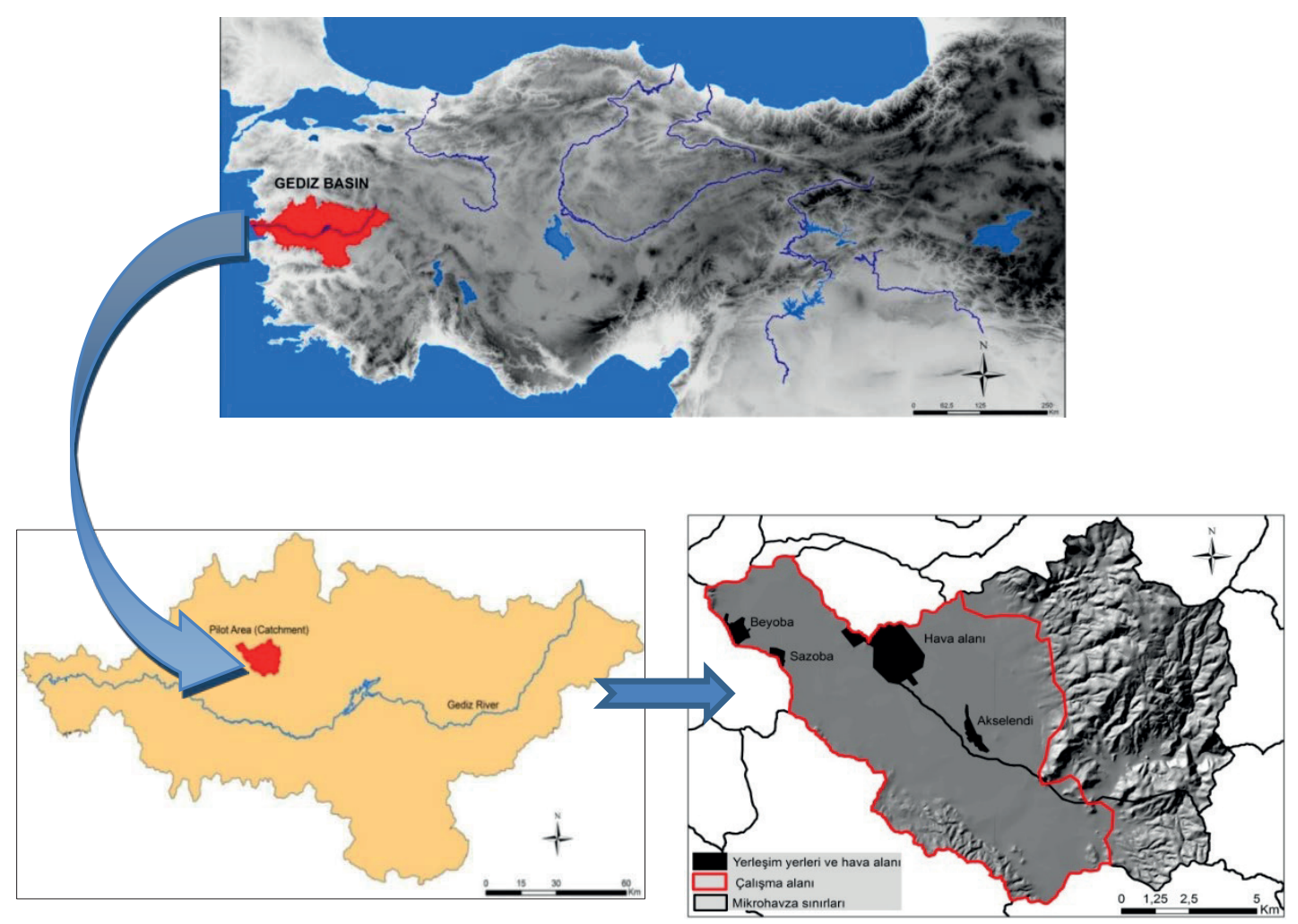

Şekil 1. Gediz Havzası'nda yer alan Ilıcak ve Kum Çayı bitişik mikro havzaların konum haritası
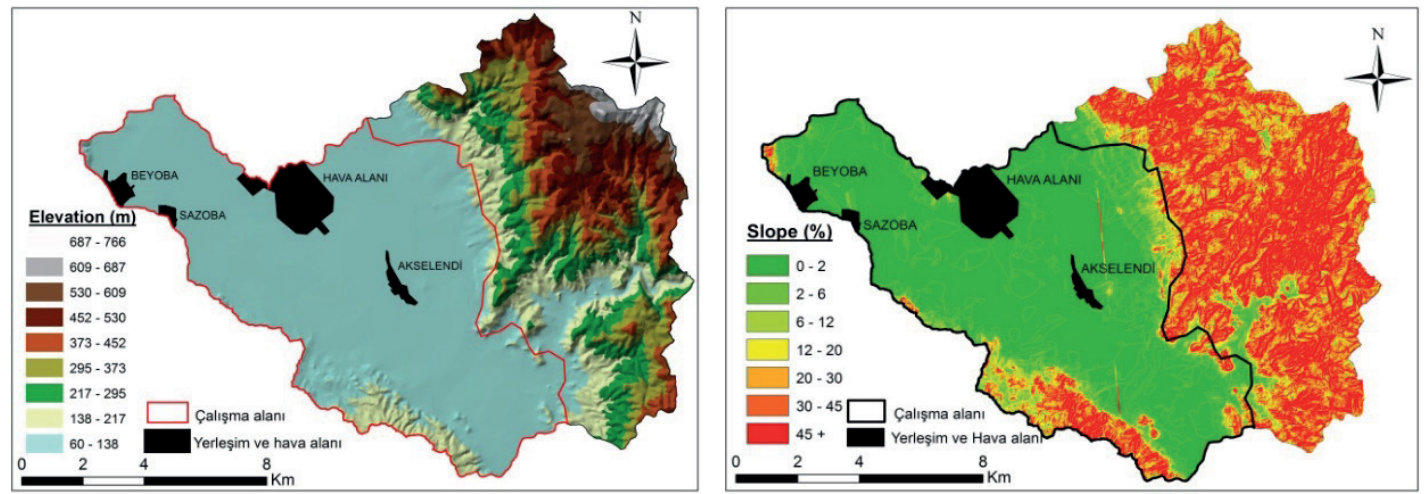

Şekil 2. Çalışma alanının ve yakın çevresine ait yükselti ve eğim haritaları

Walkley-Black yaş yakma yöntemiyle organik madde (Jackson, 1967), 1:2.5'lik toprak-su karışımında $\mathrm{pH}$ ve elektriksel iletkenlik (EC) (Anonymous, 1982), Olsen yöntemine göre alınabilir fosfor (P) içerikleri (Olsen ve Sommers, 1982); $1 \mathrm{~N}$ amonyum asetat (NH4OAc) ekstraksiyon yöntemiyle alınabilir potasyum (K) (Anonymous, 1992) ve azot (N) ise Mikro Kjeldahl metodu ile (Bremner, 1982) belirlenmiştir. Toprakların demir $(\mathrm{Fe})$, bakır $(\mathrm{Cu})$, çinko $(\mathrm{Zn})$ ve mangan $(\mathrm{Mn})$ içerikleri ise; DTPA ile ekstraksiyon sonrasında elde edilen çözeltinin atomik adsorbsiyon spektrofotometresinde okunmasıyla (Anonymous, 1990) saptanmıştır. Toprak özelliklerinin aralık sinıflarının değerlendirilmesinde, Lindsay ve Norvell (1978) ile Ülgen ve Yurtsever (1995) tarafindan bildirilen sınır değerler kullanılmıştır.

Toprak parametrelerinin değerinin alansal dağılımının belirlenmesinde en çok kullanılan enterpolasyon yöntemlerinden IDW, yöntemi kullanılmıştır. IDW enterpolasyon tekniği, deterministik bir yöntemdir (Özyazıcı ve ark., 2016). Deterministik teknikler enterpolasyon işleminde matematiksel fonksiyonları kullanırken, Stochastic (jeostatistiksel) yöntemler tahmin 
işlemindeki belirsizlik ve hataları da ortaya koyabilecek şekilde, hem matematiksel hem de istatistiksel fonksiyonları dikkate alarak işlem yapmaktadır. IDW enterpolasyon tekniği, enterpole edilecek yüzeyde yakındaki noktaların uzaktaki noktalardan daha fazla ağırlığa sahip olması esasına dayanır. $\mathrm{Bu}$ teknik, enterpole edilecek noktadan uzaklaştıkça ağırlığı da azaltan ve örnek noktaların ağırlıklı ortalamasına göre bir yüzey enterpolasyonu yapar. En fazla yakındaki veri etkilenir. Yüzey ise yakınlık derecesine bağlı olarak daha fazla ayrıntıya sahip olur (Arslanoğlu ve Özçelik, 2005).

Çalışma alanına ait elde edilen toprak analiz sonuçlarına ait tanımlayıcı istatistikler SPSS 12.0 paket programında yapılmış, uygunluk sınıfların konumsal dağılım alanlarının belirlenmesinde ise ArcGIS $10.2 \mathrm{v}$ programı kullanılmıştır.

Tablo 1. Çalışma alanı ve yakın çevresi içerisinde dağılım gösteren AK/AÖ türlerinin alansal ve oransal dağılımları

\begin{tabular}{lcc}
\hline Arazi kullanımı/Arazi örtüsü (AK/AÖ) türü & Alan (ha) & Oran (\%) \\
\hline Kesikli kırsal & 1854.9 & 1.1 \\
Havaalanları & 3564 & 2.1 \\
Mineral çıkarım sahaları & 939.6 & 0.6 \\
İnşaat sahaları & 615.6 & 0.4 \\
Sulanmayan ekilebilir alan & 356.4 & 0.2 \\
Sulanan alan & 51281.1 & 30.8 \\
Üzüm bağları & 7711.2 & 4.6 \\
Zeytinlikler & 8415.9 & 5.1 \\
Meralar & 1061.1 & 0.6 \\
Sulanmayan karışık tarım & 14588.1 & 8.8 \\
Meyveyle karı̈şı sulu & 8189.1 & 4.9 \\
Doğal bitki örtüsü ile birlikte bulunan tarım alanları & 4608.9 & 2.8 \\
Geniş yapraklı ormanlar & 591.3 & 0.4 \\
İğne yapraklı ormanlar & 24615.9 & 14.8 \\
Karışı ormanlar & 4544.1 & 2.7 \\
Doğal çayırlıklar & 8618.4 & 5.2 \\
Sklerofil bitki örtüsü & 4746.6 & 2.9 \\
Bitki değișim alanları & 16767 & 10.1 \\
Sahiller, kumsallar ve kumluklar & 2673 & 1.6 \\
Seyrek bitki alanları & 704.7 & 0.4 \\
\hline Toplam & 166446.9 & 100.0 \\
\hline
\end{tabular}

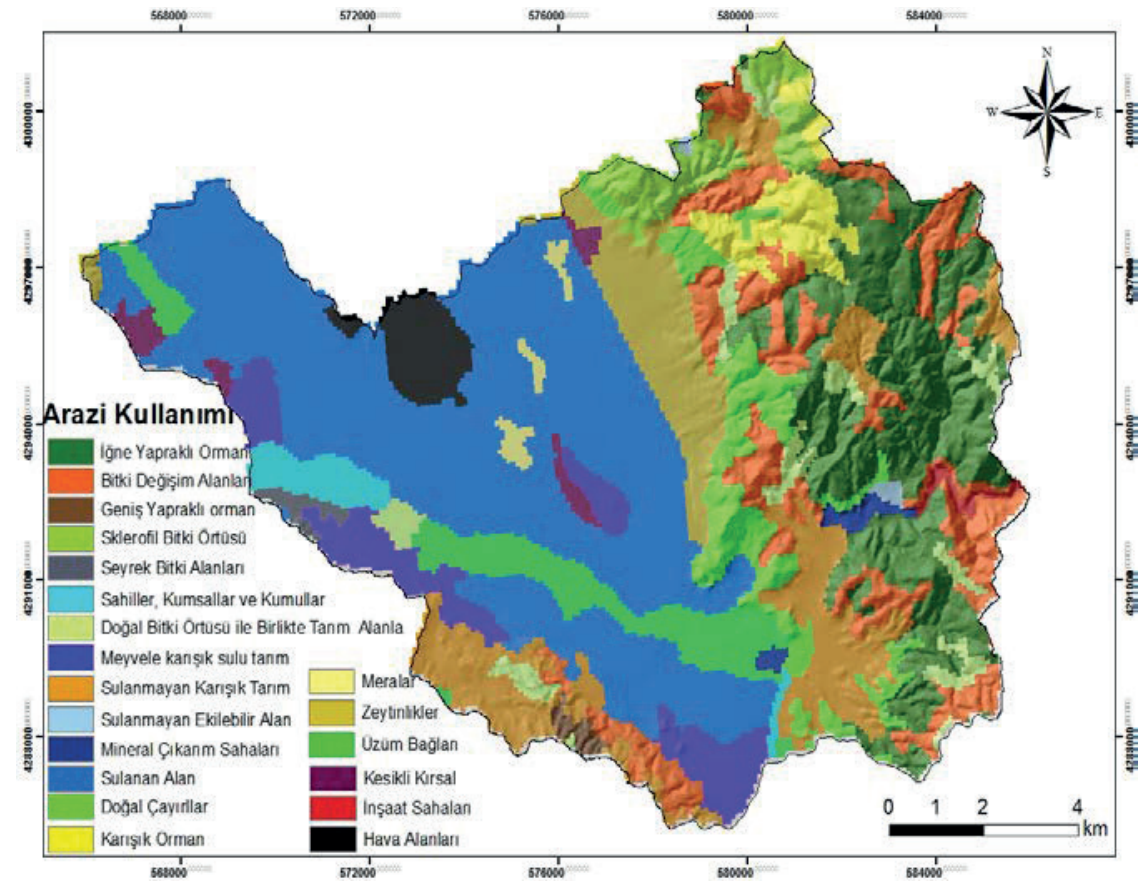

Şekil 3. CORINE-2012 sınıflamasına göre çalışma alanın arazi kullanım haritası 


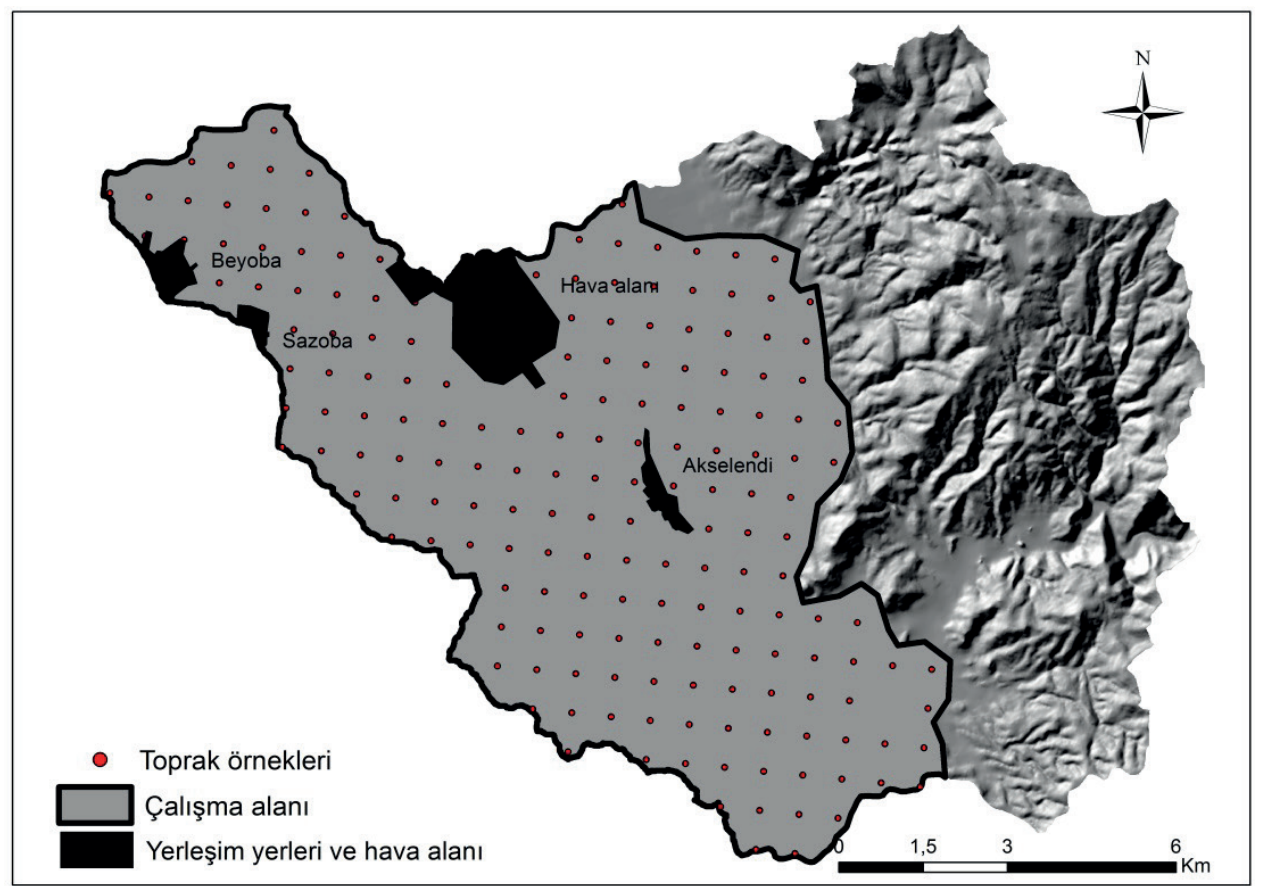

Şekil 4. Toprak örnekleme deseni

\section{Bulgular ve Tartışma}

Araştırma sahasından alınan 181 toprak örneğinin 14 adet farklı parametresi [kil, silt, kum, pH, EC, organik madde $(\mathrm{OM})$, kireç $\left(\mathrm{CaCO}_{3}\right), \mathrm{N}, \mathrm{P}, \mathrm{K}, \mathrm{Fe}$, $\mathrm{Cu}, \mathrm{Zn}$ ve $\mathrm{Mn}$ ] incelenmiş ve bu özelliklerin tanımlayıcı istatistiksel hesaplamaları yapılmıştır (Tablo 2). Bazı araştırmacılar toprak özelliklerindeki değişimlerin açıklanmasında önemli bir gösterge olarak kabul edilen değişkenlik katsayısını, aldığ 1 değerlere göre düşük $(<\% 15)$, orta $\left(\begin{array}{ll}\% & 15-35)\end{array}\right)$ ve yüksek $(>\% \quad 35)$ olarak sinıflandırmaktadırlar (Wilding, 1985; Mulla ve
Mc Bratney, 2000; Sağlam, 2013). Bu çalışmada pH, EC, OM, N, Cu ve $\mathrm{Zn}$ değişkenlik katsayıları düşük iken; silt, kum, $\mathrm{CaCO}_{3}, \mathrm{P}, \mathrm{K}$ ve $\mathrm{Mn}$ ise yüksek değişkenlik özellikleri göstermektedir. Havza tarım topraklarında $\mathrm{pH}$ 6.60-8.28 arasında değişmekte olup, normal dağılım sergilemektedir. EC değeri 0.22-1.83 $\mathrm{dS} \mathrm{m}^{-1}$ arasında değerlerde ve sağa çarpıklık göstermektedir. Kil miktarı \% 0.8029.20 , silt \% 0.50-36.90 ve kum \% 39.40-98.70 arasında değişmekte olup, kil ve silt sağa çarpık, kum ise sola çarpık dağılım gösterdiği görülmektedir (Tablo 2).

Tablo 2. Yüzey $(0-30 \mathrm{~cm})$ topraklarının fiziksel ve kimyasal özelliklerine ait tanımlayıcı istatistikleri

\begin{tabular}{|c|c|c|c|c|c|c|c|c|}
\hline $\begin{array}{l}\text { Toprak } \\
\text { özellikleri }\end{array}$ & Ortalama & $\begin{array}{l}\text { Standart } \\
\text { sapma }\end{array}$ & $\begin{array}{c}\text { Değişkenlik } \\
\text { katsayısı }^{*}\end{array}$ & Varyans & $\begin{array}{c}\text { En } \\
\text { düşük } \\
\text { değer }\end{array}$ & $\begin{array}{c}\text { En } \\
\text { yüksek } \\
\text { değer }\end{array}$ & Çarp1kl1k ${ }^{* *}$ & Basıklık \\
\hline $\mathrm{pH}$ & 7.34 & 0.267 & 1.68 & 0.072 & 6.60 & 8.28 & 0.784 & 1.537 \\
\hline $\mathrm{EC}$ & 0.64 & 0.261 & 1.61 & 0.068 & 0.22 & 1.83 & 1.305 & 3.012 \\
\hline Kil, \% & 6.76 & 4.746 & 28.40 & 22.525 & 0.80 & 29.20 & 2.084 & 5.146 \\
\hline Silt, \% & 9.23 & 6.932 & 36.40 & 48.053 & 0.50 & 36.90 & 1.700 & 3.148 \\
\hline Kum, \% & 83.98 & 10.862 & 59.30 & 117.988 & 39.40 & 98.70 & -1.734 & 3.304 \\
\hline OM, \% & 1.55 & 0.856 & 5.37 & 0.733 & 0.13 & 5.50 & 1.752 & 4.675 \\
\hline $\mathrm{CaCO}_{3}, \%$ & 8.35 & 7.159 & 49.12 & 51.251 & 0.59 & 49.71 & 2.622 & 8.900 \\
\hline $\mathrm{N}, \%$ & 0.07 & 0.043 & 0.27 & 0.002 & 0.01 & 0.28 & 1.793 & 4.863 \\
\hline $\mathrm{P}, \mathrm{mg} \mathrm{kg}^{-1}$ & 21.53 & 12.150 & 60.54 & 147.625 & 1.23 & 61.77 & 0.811 & 0.293 \\
\hline $\mathrm{K}, \mathrm{mg} \mathrm{kg}^{-1}$ & 132.63 & 80.962 & 420.26 & 6554.988 & 15.07 & 435.33 & 0.956 & 1.073 \\
\hline $\mathrm{Fe}, \mathrm{mg} \mathrm{kg}^{-1}$ & 3.45 & 2.202 & 20.55 & 4.850 & 0.82 & 21.37 & 3.894 & 25.032 \\
\hline $\mathrm{Cu}, \mathrm{mg} \mathrm{kg}^{-1}$ & 1.22 & 1.132 & 12.10 & 1.282 & 0.11 & 12.21 & 5.940 & 50.585 \\
\hline $\mathrm{Zn}, \mathrm{mg} \mathrm{kg}{ }^{-1}$ & 0.43 & 1.289 & 14.85 & 1.664 & 0.00 & 14.85 & 8.274 & 87.531 \\
\hline $\mathrm{Mn}, \mathrm{mg} \mathrm{kg}^{-1}$ & 15.00 & 13.446 & 90.57 & 180.795 & 1.66 & 92.23 & 3.249 & 13.800 \\
\hline
\end{tabular}

*: Değişkenlik katsayısı: $<15=$ Düşük değişkenlik, 15-35 = Orta değişkenlik, $>35=$ Yüksek değișkenlik,

${ }^{* *}:$ Çarpıklık: $<|\mp 0.5|=$ Normal dağılım, $0.5-1.0=$ Veri setine karakter dönüşümü uygulanır, ÇK $>1.0 \rightarrow$ Logaritma dönüşümü uygulanır 
Organik madde miktarı \% 0.13-5.50 ve $\mathrm{CaCO}_{3}$ miktarı ise \% 0.59-49.71 arasında değişmektedir. Ayrıca her iki özellik de sağa çarpık özellik göstermektedir. Azot \% 0.01-0.28, fosfor 1.23$61.77 \mathrm{mg} \mathrm{kg}^{-1}$, potasyum $15.07-435.33 \mathrm{mg} \mathrm{kg}-1$ değerleri arasında değişirken, $\mathrm{N}$ sağa çarpık özellik göstermekte, $\mathrm{P}$ ve $\mathrm{K}$ normal dağılım sergilemektedir. Mikro elementlerin durumu incelendiğinde; $\mathrm{Fe}, \mathrm{Cu}, \mathrm{Zn}$ ve $\mathrm{Mn}$ elementleri sağa çarpık dağılım göstermektedir. Fe 0.82-21.37 mg $\mathrm{kg}^{-1}, \mathrm{Cu} 0.11-12.21 \mathrm{mg} \mathrm{kg}^{-1}, \mathrm{Zn} 0.0-14.85 \mathrm{mg} \mathrm{kg}^{-1}$ ve $\mathrm{Mn} 1.66-92.23 \mathrm{mg} \mathrm{kg}^{-1}$ miktarları arasında değişmektedir. Havza tarım topraklarında normal dağılımdan en uzak değer gösteren toprak özelliğinin $\mathrm{Zn}$ olduğu, en yakın ise $\mathrm{pH}$ özelliği olduğu belirlenmiştir (Tablo 2).

Çalışma alanı tarım topraklarının temel toprak parametreleri yönünden sinır değerlerine göre sınıflandırılması Tablo 3'te verilmiştir. Çalışma alanı içerisinde yer alan Akselendi Ovası toprakların büyük bir çoğunluğu Kum Çayı'nın getirmiş olduğu alüvyal kumul depozitler üzerinde yer almaktadır. Kum Çayı'nın ovadaki yatağı oldukça düzensiz olup, gücünün fazla olduğu dönemlerde ovaya taşıdığı çok fazla miktardaki alüvyonlar üzerinde sik sik yatak değiştirmiş ve geniş bir taşkın yatağı oluşturmuştur (Öner, 1993). Taşkınlar sonrası bol miktarda kum, ince kum ve silt boyutundaki sedimentler yatak ve çevresine birikmişlerdir. Bu birikimler özellikle ovanın doğu bölümünde yer alan dağlık kesimlerden taşınmıştır. Bu nedenle toprakların bünyeleri kaba ve çok kaba olan tınlı kum ile kum arasında değişmektedir. Yalnızca yamaç arazilere yakın etek kısımlarda kil tın sınıfı orta bünyeli topraklar yer almaktadır. Kum oranı özellikle ova tabanında daha fazla yayılım gösterirken, kil oranı ise çalışma alanın güney kesimlerinde artış göstermektedir (Şekil 5).

Alınan tüm toprak örneklerine ait $\mathrm{pH}$ değerleri nötr ile hafif alkalin arasında değişmekte olup, topraklar $4 \mathrm{dS} \mathrm{m}^{-1}$ daha düşük değere sahip tuzsuz topraklardır (Tablo 3). Çalışma alanını kuzey doğusunda yer alan etek, yamaç ve yüksek arazilerde; Öner (1993) jeolojik yapının genellikle Paleozoik yaşlı mermer ve şistler, bunların üzerinde diskordant olarak gelen Mesozoik kristalli kalker, kumtaşı, marn ile Tersiyere ait kalker, marn, kumtaşı, kiltaşları yer almakta olduğunu belirtmiştir. $\mathrm{Bu}$ durum özellikle $\mathrm{CaCO}_{3}$ kaynağı olan marn, mermer, kalker gibi kireç taşlarından olan ana materyallerin ayrışması sonrası toprakta sekonder kireç birikimler oluşturabilmektedir. $\mathrm{Bu}$ durum kireç dağılım haritasında da görülmektedir. Özellikle kireç miktarının yoğun olduğu bölgeler, çalışma

Tablo 3. Çalışma alanı tarım topraklarının temel toprak parametreleri yönünden sınıflandırılması

\begin{tabular}{|c|c|c|c|c|}
\hline Toprak özellikleri & Sınır değeri & Değerlendirme & Örnek sayıs1 & $\%$ \\
\hline \multirow{5}{*}{$\begin{array}{l}\text { Bünye sınıflar1 } \\
(\%)\end{array}$} & & Kil tın (CL) & 1 & 0.6 \\
\hline & & Tinlı kum (LS) & 79 & 43.6 \\
\hline & & $\operatorname{Kum}(\mathrm{S})$ & 65 & 35.9 \\
\hline & & Kumlu kil tın (SCL) & 4 & 2.2 \\
\hline & & Kumlu tın (SL) & 32 & 17.7 \\
\hline \multirow{6}{*}{$\mathrm{pH}$} & $<4.5$ & Kuvvetli asit & -- & -- \\
\hline & $4.5-5.5$ & Orta asit & -- & -- \\
\hline & $5.5-6.5$ & Hafif asit & -- & -- \\
\hline & $6.5-7.5$ & Nötr & 139 & 76.8 \\
\hline & $7.5-8.5$ & Hafif alkali & 42 & 23.2 \\
\hline & $>8.5$ & Kuvvetli alkali & -- & \\
\hline \multirow{4}{*}{$\begin{array}{l}\mathrm{EC} \\
\left(\mathrm{dS} \mathrm{m} \mathrm{m}^{-1}\right)\end{array}$} & $0-4$ & Tuzsuz & 181 & 100.0 \\
\hline & $4-8$ & Hafif tuzlu & --- & --- \\
\hline & $8-15$ & Orta derecede tuzlu & --- & --- \\
\hline & $>15$ & Çok fazla tuzlu & --- & --- \\
\hline \multirow{5}{*}{$\begin{array}{l}\mathrm{CaCO}_{3} \\
(\%)\end{array}$} & $<1.0$ & Az kireçli & 3 & 1.7 \\
\hline & $1.0-5.0$ & Kireçli & 57 & 31.5 \\
\hline & $5.0-15.0$ & Orta kireçli & 102 & 56.4 \\
\hline & $15.0-25.0$ & Fazla kireçli & 9 & 5.0 \\
\hline & $>25.0$ & Çok fazla kireçli & 10 & 5.5 \\
\hline \multirow{5}{*}{$\begin{array}{l}\text { Organik madde } \\
(\%)\end{array}$} & $<0.5$ & Çok az & 10 & 5.5 \\
\hline & $0.5-1.0$ & $\mathrm{Az}$ & 37 & 20.4 \\
\hline & $1.0-2.0$ & Orta & 100 & 55.2 \\
\hline & $2.0-3.0$ & İyi & 23 & 12.7 \\
\hline & $>3.0$ & Yüksek & 11.0 & 6.1 \\
\hline
\end{tabular}



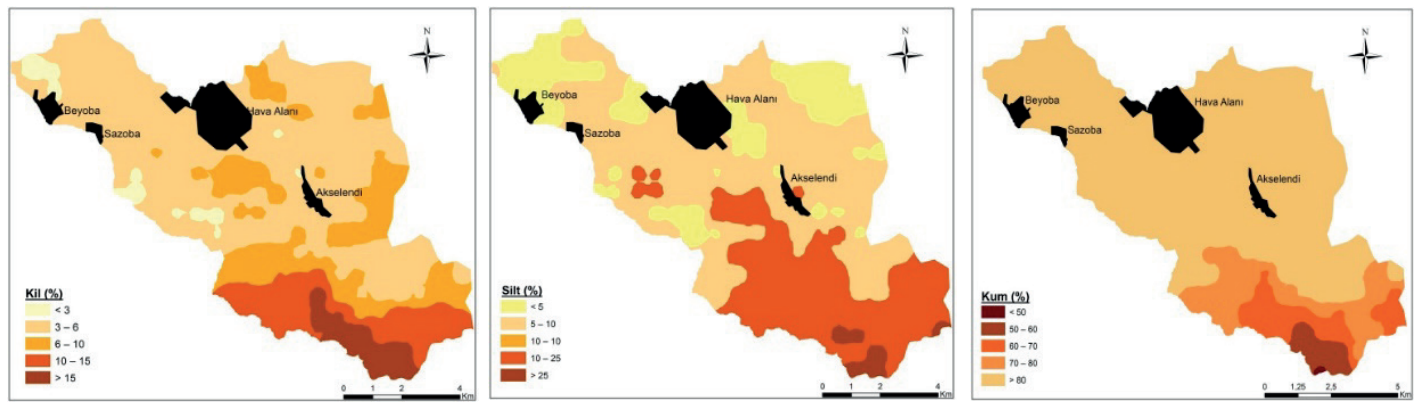

Şekil 5. Çalışma alanı içerisinde tane boyutuna ait kil, silt ve kum dağılım haritaları

alanının kuzey doğusundaki yamaç araziler ile güneydoğu kesimlerde yer alan yüksek arazilerde daha yoğun olduğu görülmektedir (Şekil 6). Toprakların çoğunluğu orta kireçli sınıfta yer almaktadırlar (Tablo 3). Toprakların organik madde dağılımları ise kaba bünyeli ve tarım yapılan taban arazilerde oldukça az ve az seviyelerinde dağılım gösterirken, bünyenin biraz inceldiği ve mera alanlarında içerisinde yer aldığ 1 etek arazilerde bu oran daha da artmaktadır. Ülgen ve Yurtsever (1995)'e göre yapılan sınıflandırma sonucunda \% 25.9'u az ve çok az sinıfta yer almakta iken, \% 55.2'si genel olarak toprakların organik madde miktarı orta düzeydedir. Yalnızca toprakların $\% \quad 18.8$ 'i yeter düzeyde dağılım göstermektedir (Tablo 3, Şekil 6).
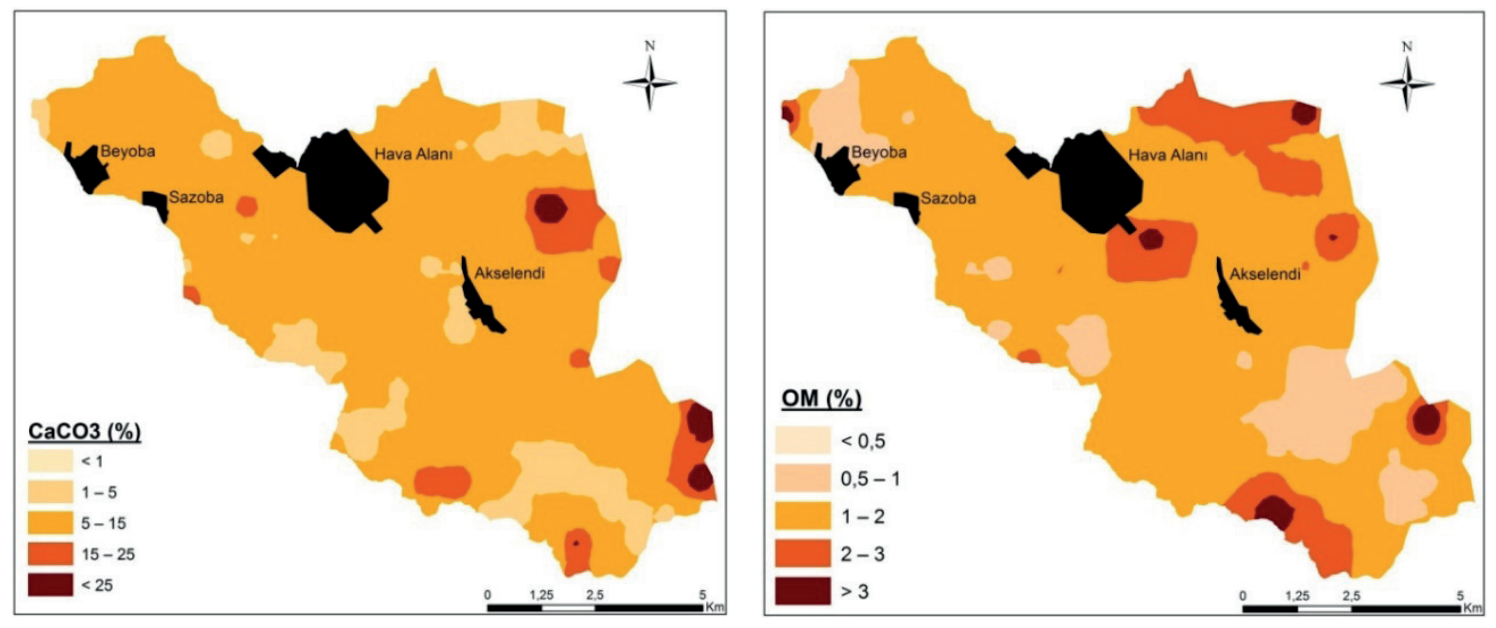

Şekil 6. Toprakların $\mathrm{CaCO}_{3}$ ve organik madde dağılım haritaları

Araştırma alanı topraklarının bazı makro besin elementi içeriklerine ait sınıflandırma değerleri Tablo 4'te verilmiştir. Tarım topraklarının alınabilir P içerikleri ortalama $23.53 \mathrm{mg} \mathrm{kg}^{-1}$ olup, 1.23 ile $61.77 \quad \mathrm{mg} \quad \mathrm{kg}^{-1}$ arasında değiştiği belirlenmiştir (Tablo 2). Tablo 4'teki sınıflandırmaya göre; toprak örneklerinin büyük bir çoğunluğu (\% 91.2) orta ve yüksek seviyede alınabilir P içerirken, \% 8.9'u ise çok az ve az seviyede olduğu belirlenmiştir (Şekil 7). Alanın büyük bir çoğunluğunun orta ve yüksek seviyede P içeriğine sahip olmasının en önemli sebebi yoğun tarımsal faaliyetler altında olmasıdır. Özellikle de $\mathrm{P}$ elementinin inmobil (hareketsiz) karakterde olması topraklarda birleşmenin olduğunu göstermektedir.

Toprakların toplam $\mathrm{N}$ içeriğgi incelendiğinde; toprak örneklerinin yaklaşık üçte birinin (\% 31.5) yeterli ve fazla seviyede olduğu, büyük bir çoğunluğunun (\% 68.5) az ve çok az düzeyde toplam N içerdiği saptanmıştır (Tablo 4, Şekil 7). Bu durum özellikle fosforun tersine, her ne kadar yoğun tarımsal faaliyet yapılsa dahi, azotun gerek çok hareketli bir besin elementi olması, gerekse de bünyenin özellikle alanın orta ve kuzeybatı ve güney doğu kesimlerinin kaba ve çok kaba olması, bu sonuca neden olabilmektedir. 
Tablo 4. Çalışma alanı tarım topraklarının bazı makro elementler yönünden sınıflandırılması

\begin{tabular}{lllcc}
\hline Toprak özellikleri & Sinır değeri & Değerlendirme & Örnek sayıs & $\%$ \\
\hline & $<0.045$ & Çok az & 34 & 18.8 \\
Toplam N & $0.045-0.090$ & Az & 90 & 49.7 \\
$(\%)$ & $0.090-0.170$ & Yeterli & 47 & 26.0 \\
& $0.170-0.320$ & Fazla & 10 & 5.5 \\
& $>0.320$ & Çok fazla & -- & -- \\
\hline & $<2.5$ & Çok az & 3 & 1.7 \\
Alınabilir P & $2.5-8$ & Az & 13 & 7.2 \\
$\left(\right.$ mg kg $\left.^{-1}\right)$ & $8-25$ & Orta & 106 & 58.6 \\
& $25-80$ & Yüksek & 59 & 32.6 \\
& $>80$ & Çok yüksek & -- & -- \\
\hline & $<100$ & Çok düşük & 71 & 39.2 \\
Alınabilir K & $100-150$ & Düşük & 42 & 23.2 \\
$\left(\mathrm{mg} \mathrm{kg}^{-1}\right)$ & $150-200$ & Orta & 37 & 20.4 \\
& $200-250$ & İyi & 16 & 8.8 \\
& $250-320$ & Yüksek & 9 & 5.0 \\
& $>320$ & Çok yüksek & 6 & 3.3 \\
\hline
\end{tabular}

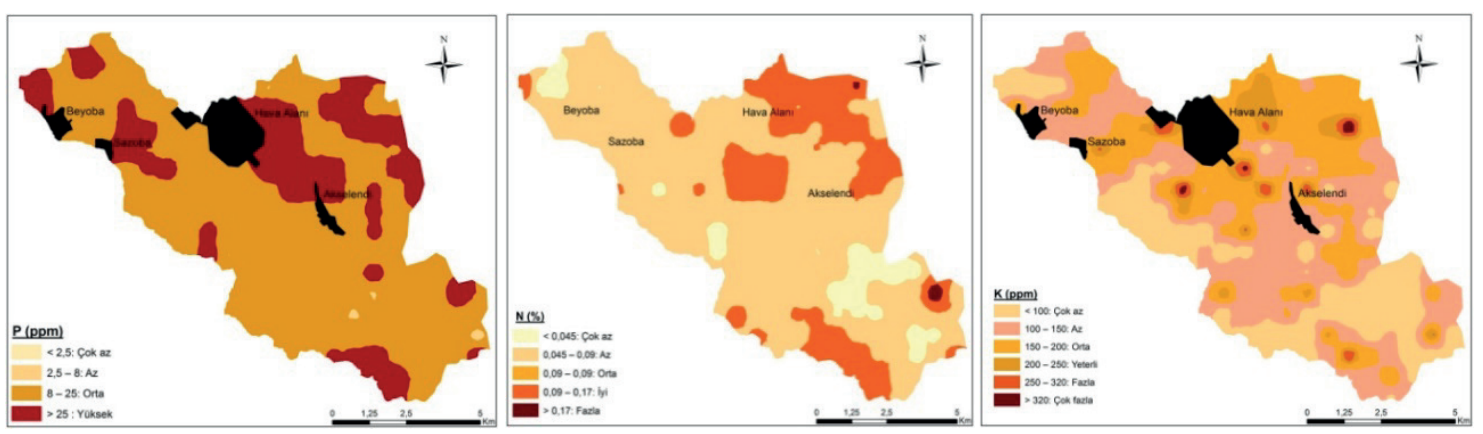

Şekil 7. Makro besin elementlerinin çalışma alanı içerisindeki dağılım haritaları

Toprakların alınabilir K içerikleri 15.07-435.33 mg kg-1 arasında değişiklik göstermiştir (Tablo 3). Tablo 4'ten görüleceği üzere; toprakların \% 52.4'ü çok düşük ve düşük, \% 20.4'ü orta, \% 17.1 iyi, yüksek ve çok yüksek düzeyde alınabilir K içerdiği belirlenmiştir (Şekil 7). Toprakların en önemli K kaynaklarından birisi içerdikleri kil miktarı ve kil çeşididir. Toprakların $\mathrm{K}$ içeriklerinin yaklaşık yarısından fazlasında yetersiz $\mathrm{K}$ olması bu alanlardaki toprakların bünyelerinin kaba olmasından kaynaklanmaktadır.

Araştırma alanı topraklarının Lindsay ve Norvell (1978) tarafindan bildirilen kriterlere göre mikro besin elementi içeriklerinin sınıflandırılması Tablo 5'te, dağılım haritaları ise Şekil 8'de verilmiştir. Çalışma alanı içerisinde $\mathrm{Cu}$ eksikliği belirlenmemiştir. Fakat $\mathrm{Fe}, \mathrm{Mn}$ ve $\mathrm{Zn}$ içerikleri yönünden, alınan toprak örneklerinin büyük bir çoğunluğunda eksikliğin söz konusu olduğu saptanmıştır (Tablo 5). Bu durum dağılım haritalarında da belirgin olarak görülmektedir.

\section{Sonuç ve Öneriler}

Toprağın kum, silt ve kil gibi farklı tanecik çaplarına sahip fraksiyonların belirli oranlarda karışımlarından oluşan bünye özelliği, toprakların verimlilik seviyeleri üzerine etki eden en önemli fiziksel özelliklerinden birisidir. Araştırma alanı tarım topraklarının büyük bir çoğunluğu (\% 97.2) kaba bünyeli olup tınlı kum, kum ve kumlu tın bünyelerden oluşmaktadır. $\mathrm{Bu}$ durumda kil ve organik madde içeriklerinin düşük ve bünyenin kaba ve çok kaba olması nedeniyle bitkilerin gelişmesi için gerekli su ve bitki besin maddelerini tutulasında problemlerle karşılaşılabilmektedir. $\mathrm{Bu}$ nedenle, yörelerde toprakların organik madde seviyesinin iyileştirilmesi yönünde gerekli önlemlerin alınması, hem toprak verimliliği ve toprakların sürdürülebilirliği açısından, hem de yetiştirilen ürünlerin verim ve kalitesi açısından büyük önem taşımaktadır. $\mathrm{Bu}$ amaçla, toprakların özellikle yapısal iyileştirmelerin yapılmasında, yaklaşık 3 yılda dekara 2-3 kg iyi fermente olmuş 
Tablo 5. Çalışma alanı tarım topraklarının bazı mikro elementler yönünden sınıflandırılması

\begin{tabular}{lllcc}
\hline Toprak özellikleri & Sınır değeri & Değerlendirme & Örnek sayıs & $\%$ \\
\hline \multirow{2}{*}{$\begin{array}{l}\text { Ekstrakte edilebilir Fe } \\
\left(\mathrm{mg} \mathrm{kg}^{-1}\right)\end{array}$} & $<2.5$ & Noksan (az) & 56 & 30.9 \\
& $2.5-4.5$ & Noksanllk gösterebilir (orta) & 95 & 52.5 \\
\hline $\begin{array}{l}\text { Ekstrakte edilebilir Cu } \\
\left(\mathrm{mg} \mathrm{kg}^{-1}\right)\end{array}$ & $>4.5$ & İyi (yüksek) & 30 & 16.6 \\
\hline & $<0.2$ & Yetersiz & -- & -- \\
& $>0.2$ & Yeterli & 181 & 100 \\
\hline Ekstrakte edilebilir Zn & $<0.2$ & Çok az & 134 & 74.0 \\
$\left(\mathrm{mg} \mathrm{kg}^{-1}\right)$ & $0.2-0.7$ & Az & 20 & 11.0 \\
& $0.7-2.4$ & Yeter & 23 & 12.7 \\
& $2.4-8.0$ & Fazla & 4 & 2.2 \\
& $>8.0$ & Çok fazla & -- & -- \\
\hline & $<4$ & Çok az & 16 & 8.8 \\
$\left(\mathrm{mg} \mathrm{kg}^{-1}\right)$ & $4-14$ & Az & 95 & 52.5 \\
& $14-50$ & Yeter & 65 & 35.9 \\
& $50-170$ & Fazla & 5 & 2.8 \\
\hline
\end{tabular}

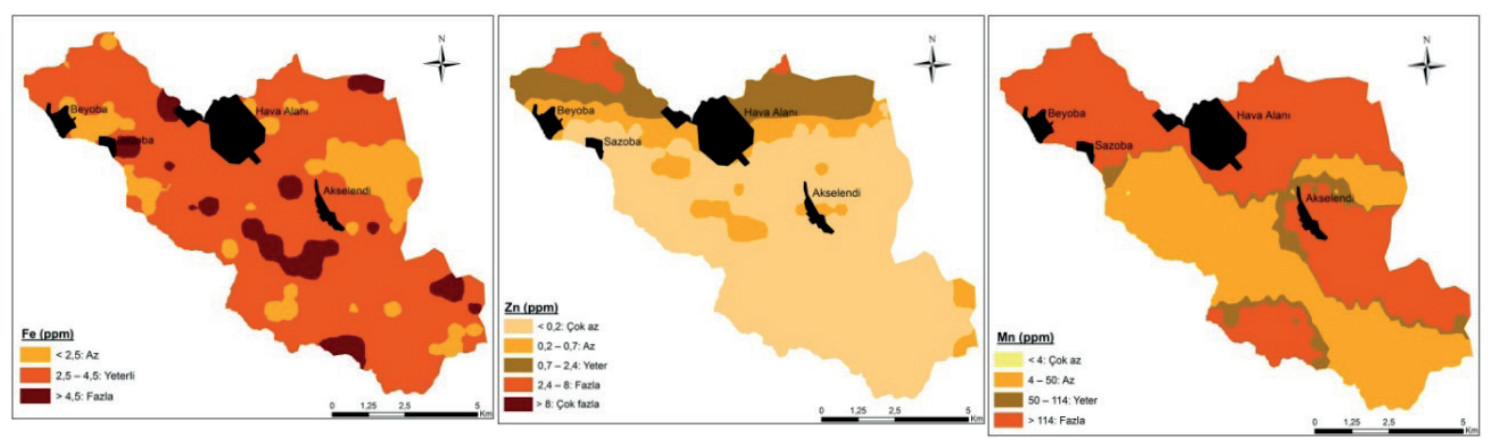

Şekil 8. Mikro besin elementlerinin çalışma alanı içerisindeki dağılım haritaları

ahır gübresi uygulanması önerile bilinir. Ayrıca bitkinin su ihtiyacının zamanında ve yeterince karşılanmasına yönelik olarak yörede yaygın bir şekilde kullanılan damla sulama sistemleri ile aşılmaya çalışılmakla birlikte; gerek yapraktan gerekse de sulama suları ile birlikte özellikle mikro besin elementi takviyesi yapılmaya çalışılmaktadır. Bölgenin en önemli diğer bir sorunu ise tarım alanlarını tehdit eden kumul hareketliliğidir. Tarım alanlarına yönelik bu tehdidin ortadan kaldırılması için gerekli önlemlerin alınması da gerekmektedir.

\section{Kaynaklar}

Arslanoğlu, M., Özçelik, M., 2005. Sayısal arazi yükseklik verilerinin iyileştirilmesi. TMMOB Harita ve Kadastro Mühendisleri Odası 10. Türkiye Harita Bilimsel ve Teknik Kurultayl, 28 Mart-01 Nisan, Ankara.

Anonymous, 1982. Methods of Soil Analysis-Part II, Chemical and Microbiological Properties. Agronomy Monograph, No: 9, ASA-SSSA, Madison, Wisconsin, USA, pp. 323-336.

Anonymous, 1990. Micronutrient, Assessment at the Country Level: An International Study. FAO, Soils Bulletin by Mikko Sillanpaa, Rome.
Anonymous, 1992. Soil Survey Staff, Procedures for Collecting Soil Samples and Methods of Analysis for Soil Survey. Soil Surv. Invest. Rep. I. U.S. Gov. Print. Office, Washington D.C. USA.

Bouyoucos, G.J., 1951. A Recalibration of the hydrometer method for making mechanical analysis of soil. Agronomy Journal, 43: 434-438.

Bremner, J.M., Mulvaney, C.S., 1982. Nitrogen-Total. In: Page, A.L., Miller, R.H., Keeney, D.R (Eds.), Methods of Soil Analysis, Part 2. Chemical and Microbiological Properties. 2 nd ed., Agronomy, 9: 595-624.

Jackson, M.L., 1967. Soil Chemical Analysis. Prentice Hall of India Private Limited, NewDelhi.

Lindsay, W.L., Norvell, W.A., 1978. Development of a DTPA Soil Test For Zinc, Iron, Manganese and Copper. Soil Science Society of America Journal, 42(3):421-428.

Mueller, L., Schindler, U., Mirschel, W., Shepherd, T.G., Ball, B.C., Helming, K., Rogaski, J., Eulenstein, F., Wiggering, H., 2010. Assessing the productivity function of soils, A reviwe. Agronomy for Sustainable Development, 30(3): 601-614.

Mulla, D.J., Mc Bratney, A.B., 2000. Soil Spatial Variability. Handbook of SoilScience CRS Pres., pp. 321-352. 
Nelson, D.W., Sommers, L.E., 1982. Total Carbon, Organic Carbon, Organic Matter. In: AL Madison (Ed.), Methods of Soil Analysis Part 2. Chemical and Microbiological Properties Second Edition. Wisconsin, USA, American Society of Agronomy Inc., pp. 539-579.

Olsen, S.R., Sommers, E.L., 1982. Phosphorus availability indices. Phosphorus soluble in sodium bicarbonate. (Eds: A.L. Page, R.H. Miller, D.R. Keeney), Methods of Soils Analysis, Part II., Chemical and Microbiological Properties, p. 404430.

Özyazıcı, M.A., Dengiz, O., Aydoğan, M., Bayraklı, B., Kesim, E., Urla, Ö., Yıldız, H., Ünal, E., 2016. Orta ve Doğu Karadeniz Bölgesi tarım topraklarının temel verimlilik düzeyleri ve alansal dağılımları. Anadolu Tartm Bilimleri Dergisi, 31(1): 136-148.

Öner, E., 1993. Akselendi Ovasında kumul oluşumu ve buna bağlı çevresel sorunlar. Ege Coğrafya Dergisi, 7: $133-160$.
Pierece, F., Larson, W., Dowy, R., Graham, W., 1983. Productvity of soils; Assessing long term changes due to erosion. Journal of Soil and Water Conservationi, 38(1): 39-44.

Ülgen, N., Yurtsever, N., 1995. Türkiye Gübre ve Gübreleme Rehberi (4. Baskı). T.C. Başbakanlık Köy Hizmetleri Genel Müdürlügü, Toprak ve Gübre Araştırma Enstitüsü Müdürlüğü Yayınları, Genel Yayın No: 209, Teknik Yayınlar No: T.66, Ankara.

Sağlam, M., 2013. Çok değişkenli istatistiksel yöntemler ile toprak özelliklerinin gruplandırılması. Toprak Su Dergisi, 2(1): 7-14.

Wilding, L.P., 1985. Spatial variability: It's documentation, accommodation and implication to soil surveys. In: D.R. Nielsenand, J. Bouma (Eds.), Soil Spatial Variability, Pudoc, Wageningen, pp: 166-194. 